\title{
On the Chain Initiation Mechanism in the High Temperature Oxidation Process of C8 Alkane
}

\author{
Qu Yakun, Long Jun and Zhou Han
}

Research Institute of Petroleum Processing, SINOPEC, Beijing 100083

Keywords: gasoline; combustion chemistry; chain initiation; DFT

\begin{abstract}
To study all kinds of elementary reactions at the level of gasoline hydrocarbon molecules has always been a core content of basic combustion research, but for a long time, studies often focus on the physical process in cylinder and don't go deep into chemical details about the molecular structure and combustion mechanism of fuel, thereby restricting the feasibility to seek control and optimize combustion process from the perspective of chemical reaction. In this paper, we study the chain initiation reaction mechanism in the high temperature oxidation process of gasoline C8 hydrocarbon molecules and explain the relationship between the structure of hydrocarbon molecules and the middle-chain initiation characteristics of pre-flame reaction of hydrocarbon molecules at a molecular level using a theoretical chemical method. It is of great significance for petroleum refining and engine designers.
\end{abstract}

\section{Introduction}

Automotive energy has been a core issue in energy-environment-economy. By the end of 2010, the prevalence of automobiles in the world had reached 134.6 per thousand people [1]. The number and proportion of passenger cars increase sharply. Cars enter families and make the sales of passenger cars increase substantially. In terms of the technical form of vehicle power, almost $100 \%$ of energy conversion is done with an internal combustion engine. In terms of the proportion in car sales, the proportion of gasoline cars is up to $75 \% \sim 80 \%$, but the total installed power of gasoline engines fitted on cars is only $66 \% \sim 71 \%$ of the total engine power of cars [2]. Therefore, the combustion efficiency of spark- ignition engine leaves much to be desired.

According to the working principle of internal combustion engine, one of the important channels to increase engine power is to increase the compression ratio of engines. However, with the improvement of engine compression ratio, in terms of fuel, it is important that the tendency that fuel produces knocks will increase, too[3]. Therefore, for years knock has been a huge obstacle to the development and use of internal combustion engines.

The knocks in spark-ignition engines refer to abnormal combustions caused by the spontaneous combustion of the last unburnt mixture after ignition before a normal flame arrives. At the end of a compression stroke, both the temperature and pressure in the cylinder gradually increase. The unburnt mixture begins a series of pre-flame reactions. After the spark plug ignites the mixture, the flame gradually advances the unburnt mixture. At this moment, the concentrations of peroxides and free radicals of peroxides in the last unburnt mixture also gradually increase. Due to high compression and thermal radiation, the temperature of the unburnt mixture rises rapidly. Peroxides in the fuel decompose sharply. Branching chain reaction makes the reaction tend to blast, burst into flames and produce knocks. The spontaneous combustion of the last unburnt mixture is closely related to the oxidation characteristic of hydrocarbons.

With the rapid development of high precision analysis and characterization technology at home and abroad, the current understanding of gasoline products has been elevated to a molecular level. There are more than 300 kinds of components in gasoline products [4]. Actual gasoline is a mixture of hundreds of hydrocarbon fuel molecules with continuous spectral changes. Generally, the number of $\mathrm{C}$ atoms is $4 \sim 12$. The distillation range is $30 \sim 220^{\circ} \mathrm{C}$, including straight-chain paraffin, isoparaffin, 
cycloparaffin, olefin, sundex and oxygen-bearing agent, etc[5]. Research on all kinds of elementary reactions at the level of gasoline hydrocarbon molecules and their reaction rates [6] has been a core content of basic combustion research. But for a long time, studies often focus on the physical process in cylinders, such as the improvement and promotion of spray, evaporation and turbulence model, but ignore the importance of fuel chemistry and don't go deep into chemical details about the molecular structure and combustion mechanism of fuel components, thereby restricting the feasibility to seek control combustion and optimize combustion concept from the perspective of chemical reaction.

Under this background, in this paper, we study the chain initiation reaction mechanism in the high temperature oxidation process of gasoline C8 hydrocarbon molecules using a theoretical chemical method, explain the chain initiation characteristics of pre-flame reaction of hydrocarbon molecules at a molecular level and gain a deep insight into the essence of knocks, so as to avoid or reduce the harms of knocks. It is of great significance for petroleum refining and engine designers.

\section{Calculation Method and Model}

Due to the complexity and volatility of actual fuel components, it is hard to portray actual fuel accurately[7]. To simulate the physical and chemical properties of actual fuel, C8 alkane normal octane, 2-methyl heptane and 2, 2, 4-trimethylpentane, whose motor octane numbers were -17, 23 and 100 respectively were selected. The molecular structural parameters in Computational Chemistry Comparison and Benchmark Database (http//cccbdb.nist.gov) were calculated, by reference to NIST. A preliminary molecular model for monomer hydrocarbon was set up. The structure is shown in Fig. 1.

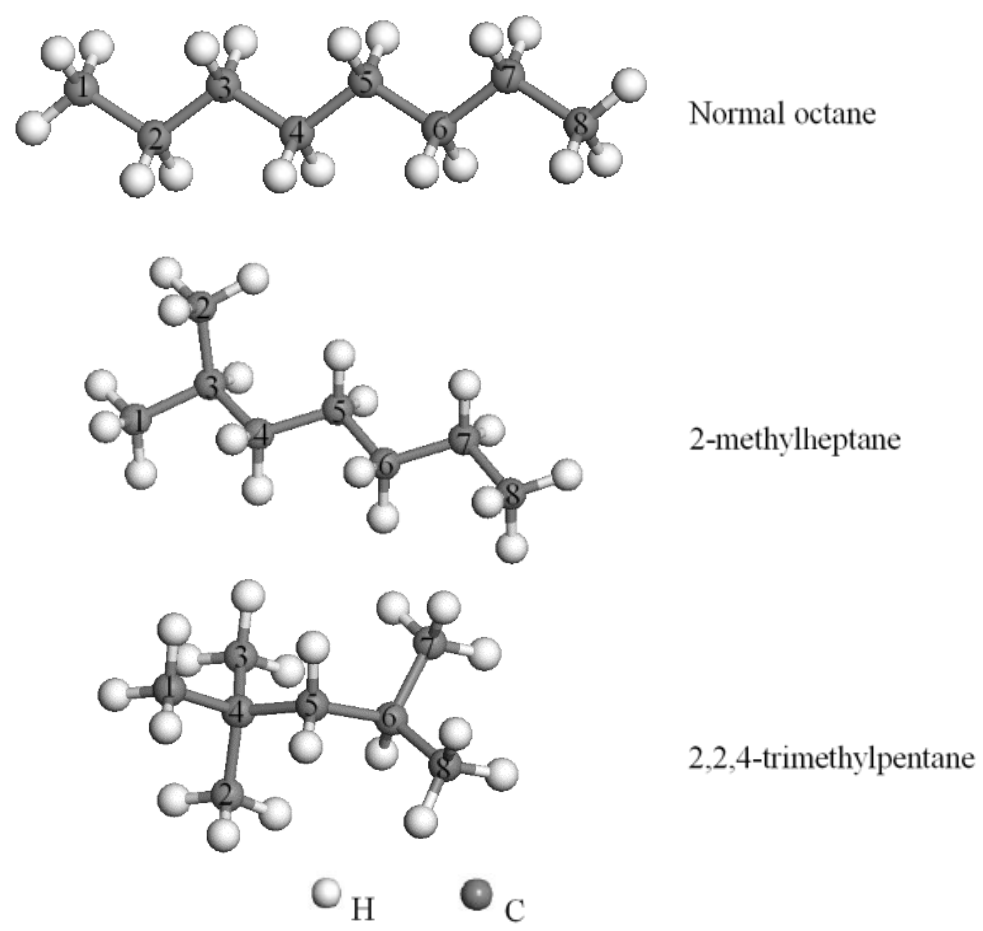

Fig. 1 The Molecular Structure of Model Compounds

By guaranteeing calculation accuracy and giving equal consideration to computational efficiency, density functional theory (DFT) in quantum stoichiometric calculation was selected for calculation. The hybrid function B3LYP $[8,9]$ was adopted. The wave function was expanded in the form of triple numerical plus polarization (TNP). The electronic processing mode was full electronic.

Transition state search and calculation of geometry optimization were done with DMol3 module in BIOVIA Materials Studio 2017 R2 software package[10]. The properties of closed shell system, such as fragment analysis, energy decomposition and Hirshfeld population analysis, etc. were calculated with ADF module developed by Software for Chemistry \& Materials (SCM) team [11, 12]. The high spin state properties of open shell, etc. were calculated with BAND module [13-16].

Linear Synchronous Transit and Quadratic Synchronous Transit (LST/QST) was adopted for transition state search. The RMS convergence criterion was $0.002 \mathrm{Ha} / \AA$. The convergence criterion 
for structural optimization was $1 \times 10^{-7} \mathrm{Ha}$. The maximum stress was $1 \times 10^{-6} \mathrm{Ha} / \AA$. The maximum displacement was $1 \times 10^{-6} \AA$ and the frequency analysis showed no imaginary frequency.

The long-range interaction of DFT $+\mathrm{D}$ was corrected using TS method. The convergence of self-consistent field was accelerated using DIIS method. Hexadecapole was used for multipole expansion. The SCF convergence criterion was $1 \times 10^{-6} \mathrm{Ha}$.

The properties of two interacting segments were calculated using natural orbitals for chemical valence (NOCV) and extended transition state-natural orbitals for chemical valence (ETS-NOCV) under Kohn-Sham molecular orbital theoretical model.

NOCV derived from the Nalewajski-Mrozek valence theory. The $\psi$ of NOCV was defined as follows:

$$
\psi_{i}=\sum_{\lambda}^{M} C_{i \lambda} \lambda
$$

Where $i$ stood for the number of NOCV, $\lambda$ stood for the molecular orbital of fragment and $\mathrm{M}$ stood for the total number of molecular orbitals. $\mathrm{Ci}$ was a column vector, which contained a combination coefficient. NOCV was expressed as a linear combination of molecular orbitals. Ci and corresponding $\Psi \mathrm{i}$ of NOCV were obtained by diagonalizing "deformed density matrix", or rather, by calculating the eigenvector of "deformed density matrix". The eigenvalue vi came in pairs, while the symbols were opposite.

$$
\triangle P C_{i}=v_{i} C_{i}
$$

The total deformed density was the sum of contributions of all NOCVs:

$$
\Delta \rho(r)=\sum_{k}^{M / 2} v_{k}\left[-\psi_{-k}^{2}(r)+\psi_{k}^{2}(r)\right]=\sum_{k}^{M / 2} \Delta \rho(r)
$$

It defined how the total deformed density of charges was broken down to each NOCV.

ETS-NOCV was a new method that combined ETS with NOCV. In ETS-NOCV method, the expression of $\Delta$ Eorb was:

$$
\Delta E_{\text {orb }}=\sum_{k} \Delta E_{\text {orb }}(k)=\sum_{k}^{M / 2} v_{k}\left[-F_{-k,-k}^{T S}+F_{k, k}^{T S}\right]
$$

Where F matrix was a diagonalized Kohn-Sham matrix, a matrix about NOCV which was defined with transition state density. Each NOCV was corresponding to a $\Delta \rho \mathrm{k}$, that is, the deformed density of a charge was broken down to a certain NOCV path, i.e., a kind of electron transfer. Meanwhile, each pair of NOCV also corresponded to the interaction energy of an orbit, $\Delta$ Eorb $(\mathrm{k})$. The sum of all $\Delta$ Eorb (k) was the total interaction energy of $\mathrm{v}$ orbit, i.e., orbital interaction.

Orbital interaction can also be further assigned to different irreducible representations using ETS approach proposed by Ziegler and Rauk [17-19], i.e., we can get the contribution of $\Delta E_{\text {orb }}$ under different irreducible representations.

\section{Results and Discussion}

It is well known that the oxidation process of hydrocarbon is essentially a chain reaction process of free radicals. The chain reaction generally includes three basic steps: chain initiation, chain transfer and chain termination. Chain initiation is the first step of high temperature oxidation of hydrocarbon molecules, i.e., to generate initial free radicals from hydrocarbon molecules. If a chain initiation reaction doesn't occur, there will be no subsequent reaction process. Meanwhile, the structure of free radicals generated by chain initiation reaction will directly affect the method of subsequent chain transfer reaction.

There were two possible chain initiation modes of free radical chain reaction of gas phase oxidation between hydrocarbon molecules and oxygen. The first was direct pyrolysis, i.e., the C-C bond of hydrocarbon molecules was directly pyrolyzed as shown in Eq. (5) and produced two hydrocarbon radicals. Or the C-H bond was directly pyrolyzed as shown in Eq. (6) and produced 
hydrocarbon radical and $\mathrm{H} \cdot$ radical. The second was chain initiation involving $\mathrm{O}_{2}$. That is, $\mathrm{O}_{2}$ generated hydrogen peroxide radical $\mathrm{HO}_{2} \cdot$ and hydrocarbon radical as shown in Eq. (7). Or $\mathrm{O}_{2}$ generated the peroxide of hydrocarbon, $\mathrm{ROOH}$, by inserting into the $\mathrm{C}-\mathrm{H}$ bond. The $\mathrm{O}-\mathrm{O}$ bond of $\mathrm{ROOH}$ was pyrolyzed and generated alkyl/alkoxyl radical $\mathrm{RO} \cdot$ and hydroxyl radical $\cdot \mathrm{OH}$, as shown in Eq. (8).

Two possible chain initiation modes of gas phase oxidation between hydrocarbon molecules and oxygen:

(1)Direct pyrolysis:

Direct pyrolysis of C-C bond: $\mathrm{RH} \rightarrow \mathrm{R} 1 \cdot+\mathrm{R} 2 \cdot(5)$

Direct pyrolysis of $\mathrm{C}-\mathrm{H}$ bond: $\mathrm{RH} \rightarrow \mathrm{R} \cdot+\mathrm{H} \cdot(6)$

(2) Chain initiation involving $\mathrm{O}_{2}$ :

$\mathrm{O}_{2}$ abstracts hydrogen: $\mathrm{RH}+\mathrm{O}_{2} \rightarrow \mathrm{R} \cdot+\mathrm{HO}_{2} \cdot(7)$

$\mathrm{O}_{2}$ inserts into the $\mathrm{C}-\mathrm{H}$ bond: $\mathrm{RH}+\mathrm{O}_{2} \rightarrow \mathrm{ROOH} \rightarrow \mathrm{RO} \cdot+\cdot \mathrm{OH}(8)$

Below we will study these three chain initiation modes of the reaction between hydrocarbon molecules and oxygen:

The chain initiation reaction mechanism of direct pyrolysis of hydrocarbon molecules

In the chain initiation reaction of direct pyrolysis, the production of free radicals depends on the dissociation of molecular middle bonds. So the activation energy it requires is equal to the bond dissociation energy (BDE) dissociated in molecules with saturated valence. When molecules absorb photons whose energy is greater than BDE, they can generate free radicals. Usually bonds with small BDE in molecules will dissociate first and generate free radicals.

The BDE of $\mathrm{R}-\mathrm{X}$ bond is $\mathrm{RX}$ pyrolysis, which is the enthalpy change of $\mathrm{R}$ and $\mathrm{X}$ processes.

$$
B D E=\Delta H=\Delta f H(\mathrm{R})+\Delta f H(\mathrm{X})-\Delta f H(\mathrm{RX})
$$

Hydrocarbon molecules contain two kinds of chemical bonds: C-C bond and C-H bond. Below we will probe into the direct pyrolysis of these two kinds of chemical bonds respectively.

First of all, the BDE for the direct pyrolysis of normal octane C-C bond was studied, as shown in Tab. 1. Since normal octane had $\mathrm{C}_{2 \mathrm{~h}}$ symmetry, there was no need to calculate the BDE of each C-C bond. The optimal reaction site for the direct pyrolysis of normal octane $\mathrm{C}-\mathrm{C}$ bond was para $\mathrm{C} 2$ - para $\mathrm{C} 3$ bond at the position of $\beta .452 .59 \mathrm{~kJ} \cdot \mathrm{mol}^{-1}$ energy was required.

Tab. 1 Energy Required by the Direct Pyrolysis of Normal Octane C-C Bond

\begin{tabular}{cc}
\hline Code of C-C Bond & $\mathrm{BDE} /\left(\mathrm{kJ} \cdot \mathrm{mol}^{-1}\right)$ \\
\hline C1-C2 & 466.75 \\
C2-C3 & 452.59 \\
C3-C4 & 454.30 \\
C4-C5 & 453.76
\end{tabular}

Next, the BDE for the direct pyrolysis of normal octane C-H bond was studied, as shown in Tab. 2. The optimal reaction site for the direct pyrolysis of normal octane $\mathrm{C}-\mathrm{H}$ bond was para $\mathrm{C} 2-\mathrm{H}$ bond at the position of $\beta .476 .17 \mathrm{~kJ} \cdot \mathrm{mol}^{-1}$ energy was required.

Tab. 2 Energy Required by the Direct Pyrolysis of Normal Octane C-H Bond

\begin{tabular}{cc}
\hline Code of C-H Bond & $\mathrm{BDE} /\left(\mathrm{kJ} \cdot \mathrm{mol}^{-1}\right)$ \\
\hline $\mathrm{C} 1-\mathrm{H}$ & 493.12 \\
$\mathrm{C} 2-\mathrm{H}$ & 476.17 \\
$\mathrm{C} 3-\mathrm{H}$ & 476.43 \\
$\mathrm{C} 4-\mathrm{H}$ & 476.32 \\
\hline
\end{tabular}

By comparing two chain initiation modes for direct pyrolysis, we know that the direct pyrolysis of $\mathrm{C}-\mathrm{C}$ bond required less energy, that is, hydrocarbon molecules carried out chain initiation by means 
of direct pyrolysis. The optimal reaction path was the direct pyrolysis of $\mathrm{C}-\mathrm{C}$ bond, as shown in Fig. 2 .<smiles>CCCCCCCC</smiles>

$\mathrm{R}$

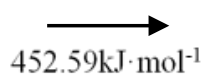

$\mathrm{C}_{2} \mathrm{H}_{5} \cdot(\mathrm{R} 1 \cdot)$<smiles>[CH2-][CH2+]CCCCC</smiles>

$\mathrm{C}_{6} \mathrm{H}_{13} \cdot(\mathrm{R} 2 \cdot)$

Fig. 2 Hydrocarbon Molecules Carried out Chain Initiation by Means of Direct Pyrolysis

Next, we studied the change rule of orbitals when the C-C bond of normal octane molecules was directly pyrolyzed, revealed the chemical nature of the direct pyrolysis of C-C bond, as shown in Fig. 3.

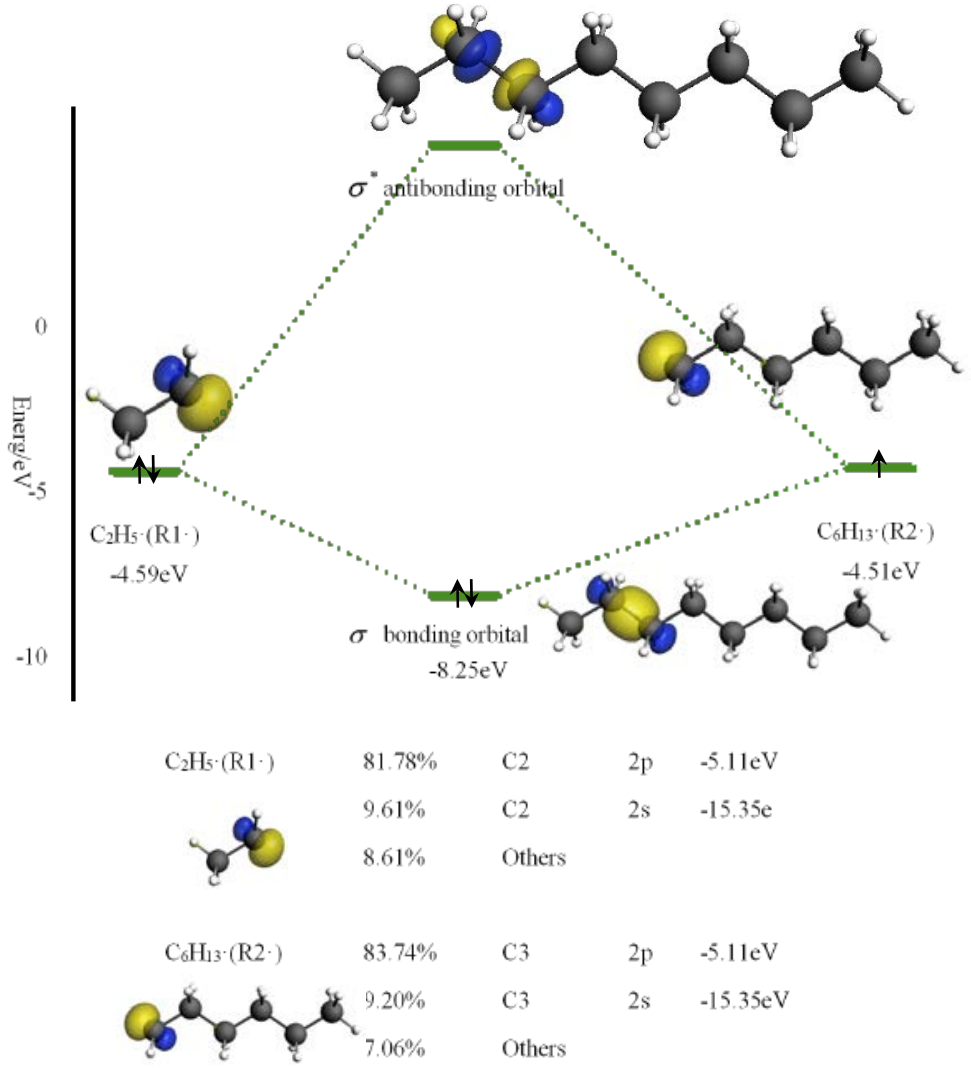

Fig. 3 The Change of NOCV during the Direct Pyrolysis of C-C Bond of Normal Octane Molecules at the Position of $\beta$

Note: Yellow stands for alpha spin (+) and blue for beta spin (-).

When the C-C bond of normal octane molecule at the position of $\beta$ was directly pyrolyzed, $\sigma_{\mathrm{C}-\mathrm{C}}$ bonding orbital (whose energy level was $-8.25 \mathrm{eV}$ ) and $\sigma_{\mathrm{C}-\mathrm{C}}^{*}$ antibonding orbital were decomposed into single occupied molecular orbitals (SOMOs) of $\mathrm{C}_{2} \mathrm{H}_{5} \cdot(\mathrm{R} 1 \cdot)$ and $\mathrm{C}_{6} \mathrm{H}_{13} \cdot(\mathrm{R} 2 \cdot)$ radicals. The main components were $2 \mathrm{p}$ and 2 s orbitals of the central $\mathrm{C}$ atom in alkyl radicals. There were also other atomic orbitals which were delocalized due to the polarization of alkyl radicals.

Later the flow of electrons when the $\mathrm{C}-\mathrm{C}$ bond of normal octane at the position of $\beta$ was directly pyrolysized was studied, as shown in Fig. 4. Based on the electron density in real space, the net flow of electrons during the direct pyrolysis of $\mathrm{C}-\mathrm{C}$ bond was $0.039 \mathrm{e}$ from $\mathrm{C}_{2} \mathrm{H}_{5} \cdot$ to $\mathrm{C}_{6} \mathrm{H}_{13} \cdot$.

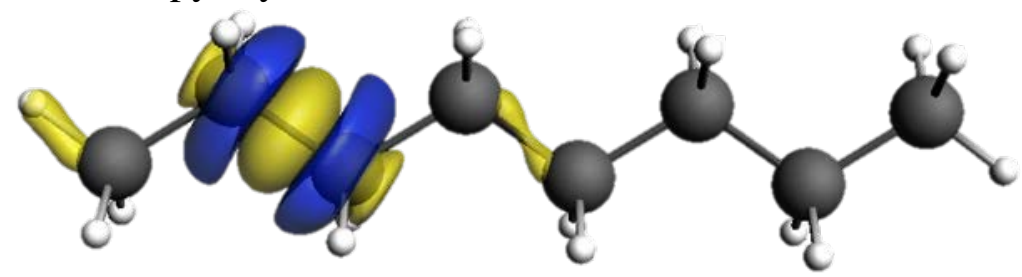

Fig. 4 The Flow of Electrons When the C-C Bond of Normal Octane Molecules was Directly Pyrolysized: Yellow $\rightarrow$ Blue 


\section{The chain initiation reaction mechanism involving $\mathbf{O}_{2}$}

In the presence of $\mathrm{O}_{2}, \mathrm{O}_{2}$ can carry out chain initiation by attacking $\mathrm{C}-\mathrm{H}$ bond and directly generating hydrogen peroxide radical $\mathrm{HO}_{2} \cdot$ and hydrocarbon radical. $\mathrm{O}_{2}$ inserted into $\mathrm{C}-\mathrm{H}$ bond and generated the peroxide of hydrocarbon, $\mathrm{ROOH}$. The $\mathrm{O}-\mathrm{O}$ bond of $\mathrm{ROOH}$ was pyrolyzed and generated alkyl/alkoxyl radical $\mathrm{RO} \cdot$ and hydroxyl radical $\cdot \mathrm{OH}$. This was also known as the chain initiation mode of gas phase oxidation process between hydrocarbon molecules and oxygen. Below, we will study them one by one.

First of all, the chain initiation process in which $\mathrm{O}_{2}$ attacked $\mathrm{C}-\mathrm{H}$ bond was studied. By calculating activation energy and enthalpy change involved in the reaction between $\mathrm{O}_{2}$ and $\mathrm{C}-\mathrm{H}$ bonds in different positions of different normal octane molecules and the generation of $\mathrm{HO}_{2} \cdot$ radical and $\mathrm{C}_{8} \mathrm{H}_{17} \cdot$ radical as shown in Tab. 3 , it was found that the minimum activation energy required by $\mathrm{O}_{2}$ attacking $\mathrm{C}-\mathrm{H}$ bond at the position of $\beta$ was $424.17 \mathrm{~kJ} \cdot \mathrm{mol}^{-1}$. The heat absorption was the smallest. The enthalpy change was $194.21 \mathrm{~kJ} \cdot \mathrm{mol}^{-1}$, so this position was where $\mathrm{O}_{2}$ molecules reacted first.

Tab. 3 The Activation Energy and Enthalpy Change When $\mathrm{O}_{2}$ Attacked the C-H Bond of Normal Octane and Generated $\mathrm{HO}_{2}$.

\begin{tabular}{ccc}
\hline $\begin{array}{c}\text { The Position of H Atom Where } \\
\mathrm{O}_{2} \text { Attacked }\end{array}$ & $\mathrm{Ea} /\left(\mathrm{kJ} \cdot \mathrm{mol}^{-1}\right)$ & $\Delta \mathrm{H} /\left(\mathrm{kJ} \cdot \mathrm{mol}^{-1}\right)$ \\
\hline C1-H & 451.91 & 238.92 \\
C2-H & 424.17 & 194.21 \\
C3-H & 429.56 & 203.83 \\
C4-H & 424.19 & 202.49 \\
\hline
\end{tabular}

In the presence of $\mathrm{O}_{2}, \mathrm{O}_{2}$ can also insert into $\mathrm{C}-\mathrm{H}$ bond and generate the radical $\cdot \mathrm{OH}$ of hydrocarbon. Below, we will study the chain initiation process in which $\mathrm{O}_{2}$ inserted into $\mathrm{C}$ - $\mathrm{H}$ bond. By calculating activation energy and enthalpy change involved in the reaction between $\mathrm{O}_{2}$ and C-H bonds in different positions of different normal octane molecules and the generation of the peroxide $\mathrm{ROOH}$, as well as the BDE involved in the dissociation of $\mathrm{O}-\mathrm{O}$ bond in $\mathrm{ROOH}$ and the generation of RO and $\cdot \mathrm{OH}$, as shown in Tab. 4 and Fig. 5, the activation energy required when $\mathrm{O}_{2}$ inserted into $\mathrm{C}-\mathrm{H}$ bond for chain initiation reaction was determined by insertion reaction. The whole process of chain initiation was endothermic reaction. The heat absorption was jointly determined by enthalpy change in the two-step reaction. The position of normal octane $\mathrm{C} 2$ atom was the optimal reaction site. The activation energy was $177.70 \mathrm{~kJ} \cdot \mathrm{mol}^{-1}$. The heat absorption was $126.18 \mathrm{~kJ} \cdot \mathrm{mol}^{-1}$.

Tab. 4 The Variation of Energy When $\mathrm{O}_{2}$ Inserted into C-H Bond for Chain Initiation

\begin{tabular}{|c|c|c|c|c|c|}
\hline $\begin{array}{c}\text { The Position } \\
\text { Where } \mathrm{O}_{2} \\
\text { Attacked } \\
\text { C-H Bond }\end{array}$ & $\begin{array}{c}\mathrm{Ea} / \\
\left(\mathrm{kJ} \cdot \mathrm{mol}^{-1}\right)\end{array}$ & $\begin{array}{c}\Delta \mathrm{H} / \\
\left(\mathrm{kJ} \cdot \mathrm{mol}^{-1}\right)\end{array}$ & $\begin{array}{l}\text { The } \\
\text { Pyrolysis } \\
\text { Position of } \\
\text { RO-OH } \\
\text { Bond }\end{array}$ & $\begin{array}{c}\mathrm{BDE} / \\
\left(\mathrm{kJ} \cdot \mathrm{mol}^{-1}\right)\end{array}$ & $\begin{array}{l}\text { Total } \Delta \mathrm{H} / \\
\left(\mathrm{kJ} \cdot \mathrm{mol}^{-1}\right)\end{array}$ \\
\hline C1-H & 238.17 & -70.07 & C1O-OH & 209.17 & 139.10 \\
\hline C2-H & 177.70 & -79.65 & C2O-OH & 205.83 & 126.18 \\
\hline C3-H & 198.46 & -76.45 & C3O-OH & 200.35 & 123.90 \\
\hline C4-H & 185.54 & -76.95 & C4O-OH & 200.89 & 123.93 \\
\hline
\end{tabular}




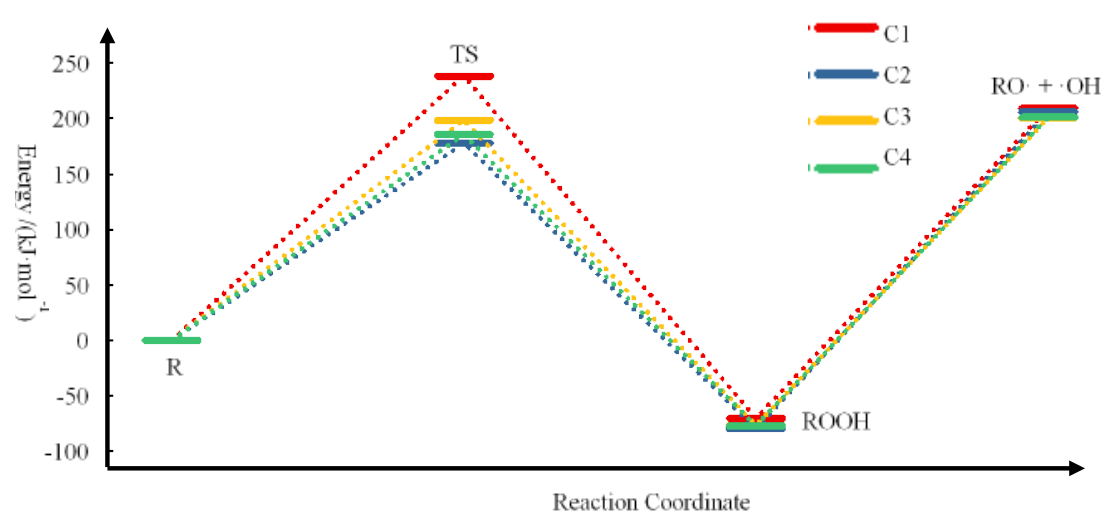

Fig. 5 The Variation of Energy When $\mathrm{O}_{2}$ Inserted into C-H Bond for Chain Initiation

To further understand the essence of reaction in which $\mathrm{O}_{2}$ was involved in the gas phase oxidation process of hydrocarbon molecules, we studied the variation process of electron orbitals of $\mathrm{O}_{2}$ during reaction, as well as the variation process of $\mathrm{C}-\mathrm{H}$ bond when $\mathrm{O}_{2}$ attacked hydrocarbon molecules, as shown in Figs. 6 and 7. The ground state of $\mathrm{O}_{2}$ molecules in the air were triplet state. The highest occupied orbital was two degenerated single occupied $\pi_{2 \mathrm{p}}^{*}$ antibonding orbitals. The 2p orbitals of two O atoms were combined linearly through "side by side" orbital overlap. The spin directions of two single electrons on orbitals were the same. The energy level was $-6.24 \mathrm{eV}$. The NOCVs where the $\mathrm{C}-\mathrm{H}$ bond of normal octane molecules was attacked by $\mathrm{O}_{2}$ were $\sigma_{\mathrm{C}-\mathrm{H}}$ bonding orbital and $\sigma_{\mathrm{C}-\mathrm{H}}^{*}$ antibonding orbital composed of $1 \mathrm{~s}$ orbital of $\mathrm{H}$ atom and highest occupied molecular orbital (HOMO) of $\mathrm{C}_{8} \mathrm{H}_{17} \cdot$ radical. Among them, the HOMO components of $\mathrm{C}_{8} \mathrm{H}_{17}$.radical were mainly hybrid orbitals of $2 \mathrm{p}$ and $2 \mathrm{~s}$ of central $\mathrm{C}$ atoms. There were also other atomic orbitals which were delocalized due to the polarization of $\mathrm{C} 8 \mathrm{H} 17 \cdot$ radical. $^{\sigma_{\mathrm{C}-\mathrm{H}}}$ bonding orbital was occupied by two electrons with opposite spin directions. The energy level was $-9.64 \mathrm{eV} . \sigma_{\mathrm{C}-\mathrm{H}}^{*}$ antibonding orbital was an unoccupied orbital. Since the spin direction of electrons on the orbital of $\mathrm{O}_{2}$ molecules, whose ground state was triplet, which were involved in the reaction didn't match that of the $\mathrm{C}-\mathrm{H}$ bond of normal octane molecules which were involved in the reaction, electrons on two degenerated orbitals singly occupied by $\mathrm{O}_{2}$ molecules had spin flip. The ground state of $\mathrm{O}_{2}$ molecules changed from triplet to singlet. In this process, $93.05 \mathrm{~kJ} \cdot \mathrm{mol}^{-1}$ heat was absorbed. The energy level of lowest unoccupied molecular orbital (LUMO) of singlet $\mathrm{O}_{2}$ rose to $-5.14 \mathrm{eV}$ and was largely different from that of the C-H bond of normal octane molecules which were involved in the reaction, so the orbital energy level of $\mathrm{O}_{2}$ molecules still needed to be adjusted. Our calculation suggested that when the energy level of singlet $\mathrm{O}_{2}$ orbital turned to a singlet fourth excited state, the energy level of LUMO fell to $-7.08 \mathrm{eV}$. The energy level difference from the $\mathrm{C}-\mathrm{H}$ bond of normal octane molecules that were involved in the reaction was reduced to $2.56 \mathrm{eV}$. The energy level difference was small. The reaction can go on smoothly. During this process, $\mathrm{O}_{2}$ absorbed $124.73 \mathrm{~kJ} \cdot \mathrm{mol}^{-1}$ heat. 


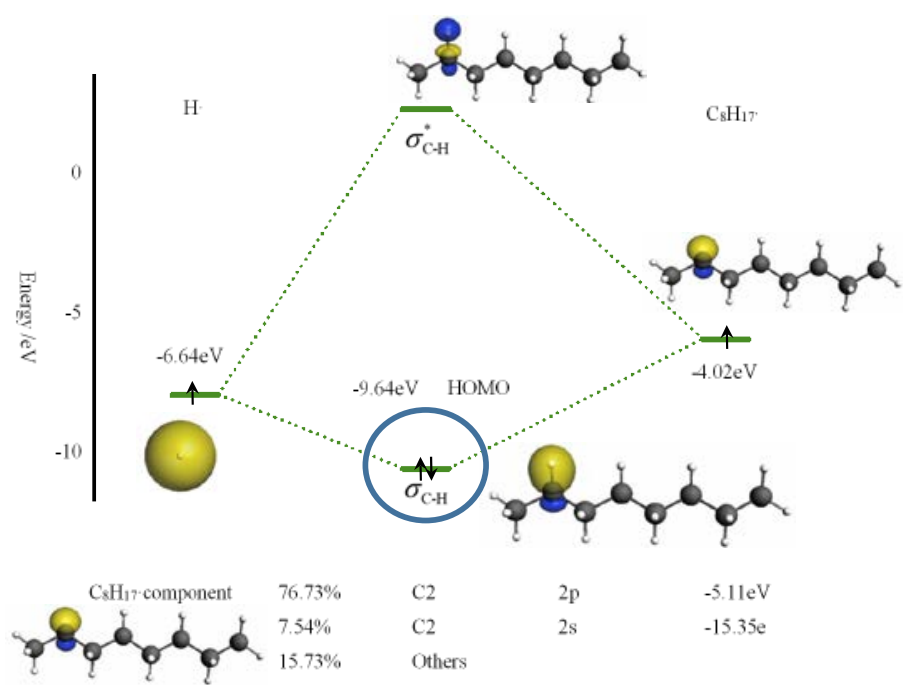

Fig. 6 The NOCV of the C-H Bond When Normal Octane Reacted with $\mathrm{O}_{2}$

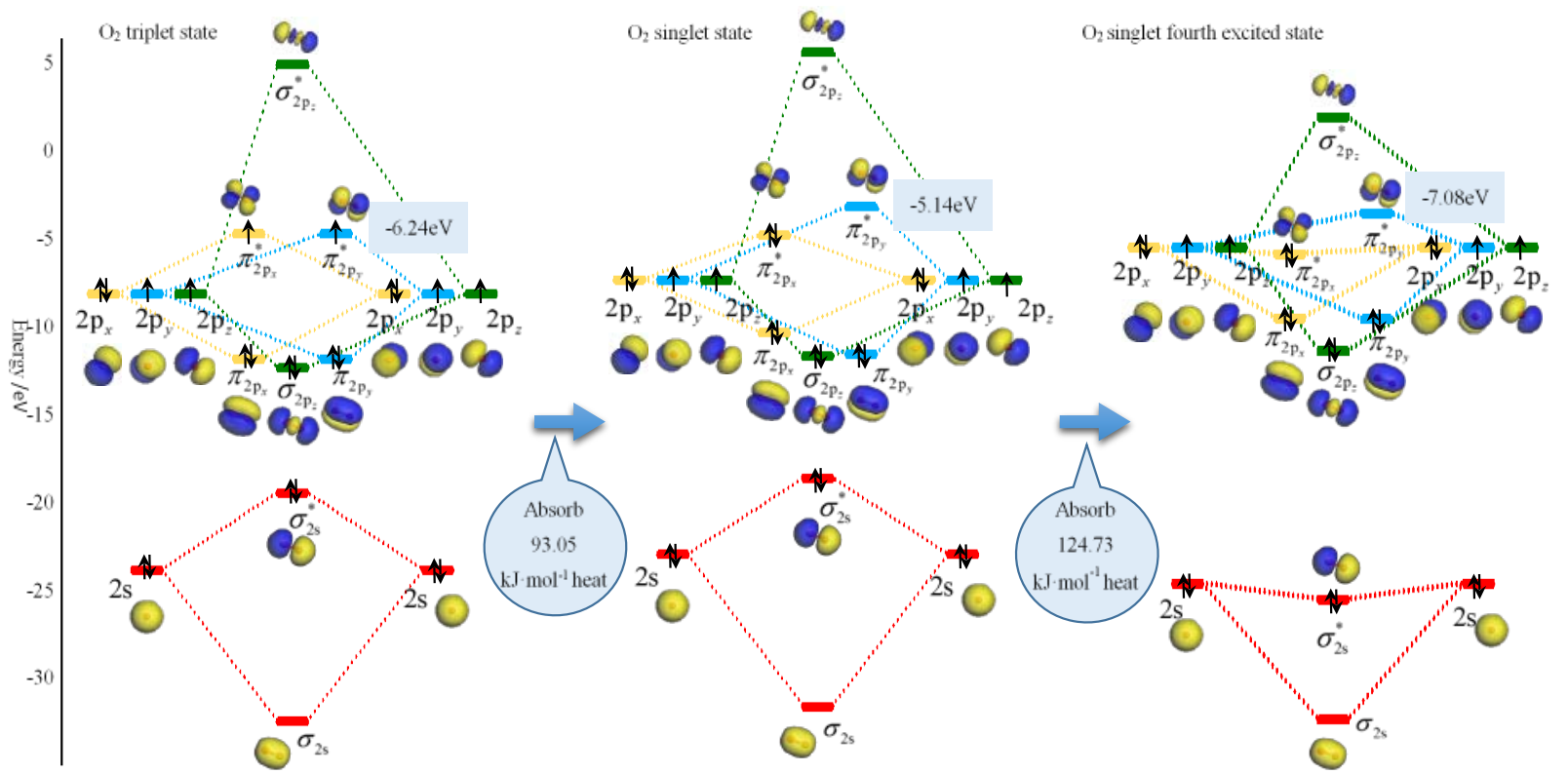

Fig. 7 The Variation of Orbitals When $\mathrm{O}_{2}$ Was Involved in the Reaction

A comparison between the chain initiation difficulty of alkane molecules with different structures

To further understand the relationship between the structure of hydrocarbon molecules and the gas phase oxidation, spontaneous combustion and even knocks of hydrocarbon molecules, we compared the relationship between the activation energy and enthalpy change during the chain initiation of C8 alkane normal octane, 2-methylheptane and 2, 2, 4-trimethylpentane, whose motor octane numbers were -17, 23 and 100 respectively and the HOMO energy level of molecules, as shown in Fig. 8. Results showed that the chain was most easily initiated in 2, 2, 4-trimethylpentane, which was associated with its high HOMO energy level. Chain initiation was just the first step of the free radical chain reaction of the spontaneous combustion of hydrocarbon molecules. It only produced the first free radical and was not a symbol of spontaneous combustion, so we cannot fully explain the rule of knocks caused by the spontaneous combustion of hydrocarbon molecules, simply by studying chain initiation modes. So we cannot say that the chain initiation of 2, 2, 4-trimethylpentane was most prone to spontaneous combustion and thus knocks. We needed to study the chain transfer process of gas phase oxidation process of hydrocarbon molecules in subsequent studies. 


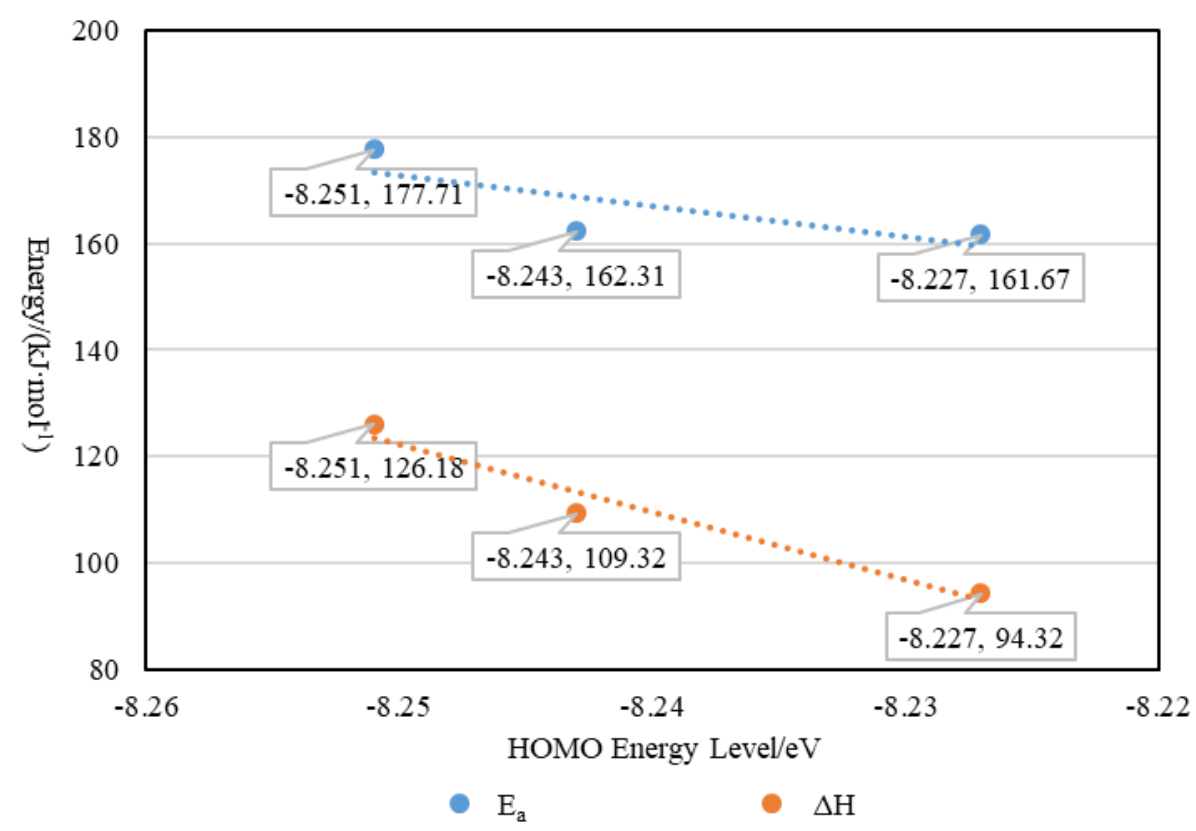

Fig. 8 The Relationship Between the Activation Energy and Enthalpy Change during the Chain Initiation of Hydrocarbon Molecules and the HOMO Energy Level of Molecules

\section{Conclusion}

To sum up, during the gas phase oxidation of hydrocarbon molecules, when the ambient temperature is low, the chain initiation process generates the peroxide $\mathrm{ROOH}$, with $\mathrm{O}_{2}$ inserting into the $\mathrm{C}-\mathrm{H}$ bond. The initial free radicals produced in the dissociation path of $\mathrm{O}-\mathrm{O}$ bond in $\mathrm{ROOH}$ are alcoxyl radical $\mathrm{RO} \cdot$ and hydroxyl radical $\cdot \mathrm{OH}$. This is because among all chain initiation reaction paths, the reaction energy barrier of this path is the lowest. When the temperature is high, $\mathrm{O}_{2}$ can attack the weakest $\mathrm{C}-\mathrm{H}$ bond in hydrocarbon molecules, generate hydrocarbon radical $\mathrm{R}$ - and peroxy radical $\mathrm{HO}_{2}$. and carry out chain initiation. In the process of flame propagation, the temperature of flame kernel is extremely high. Generally, chain initiation is achieved by the direct pyrolysis of C-C bond in hydrocarbon molecules into two hydrocarbon radicals. Meanwhile, the chain initiation difficulty of hydrocarbon molecules with different structures is mainly related to its HOMO energy level. The higher HOMO energy level, the easier it is to initiate the chain. The HOMO energy level of alkane molecules with highly branched chains is higher than those with long linear chains, so it is easier to initiate the chain. Chain initiation is just the first step in the free radical chain reaction of the spontaneous combustion of hydrocarbon molecules. It only produces the first free radical and is not a symbol of spontaneous combustion, so we cannot fully explain the rule of knock caused by the spontaneous combustion of hydrocarbon molecules simply by studying chain initiation modes. So we need to study the chain transfer process of gas phase oxidation process of hydrocarbon molecules in subsequent studies.

\section{References}

[1] China Automotive Energy Research Center, Tsinghua University, China Automotive Energy Outlook 2012. 2012, Beijing: Science Press.

[2] Zeng K, Gao K, Mao-Gang H E, et al. Recent Development in the Research of Energy Utilization Efficiency for Vehicle Engines[J]. Vehicle Engine, 2006(6): 1-4.

[3] Wang, Ning and Wen Hao, Relationship between hydrocarbon composition/structure and anti-knock property of gasoline, Petroleum Processing and Petrochemicals, 1996. 27 (2): 41-46.

[4] Liu, Yuhua, Ma Wenyou and Yu Fang, A comprehensive analysis of monomer hydrocarbon in FCC gasoline, Journal of Qiqihar University, Natural Science Edition, 1999(2): 68-69. 
[5] Allison, T.C., et al. Workshop on Combustion Simulation Databases for Real Transportation Fuels. in The Workshop on Combustion Simulation Databases for Real Transportation Fuels. 2003.

[6] Liu, Zelong, Discover the "nature" of petroleum molecules, China Petroleum and Chemical Industry, 2014(2): 50-51.

[7] Xiao, Gan, Zhang Yusheng and Jiang Guangjun, Systematic construction and validation of the reduced chemical kinetic model of gasoline multi-component surrogate fuel, Acta Physico-Chimica Sinica, 2016(4): 879-892.

[8] BecNe, A., Densityüfunctional thermochemistry. III. The role of exact exchange. J. Chem. Phys, 1993. 98: 5648-5652.

[9] Stephens, P., et al., Ab initio calculation of vibrational absorption and circular dichroism spectra using density functional force fields. The Journal of Physical Chemistry, 1994. 98(45): 11623-11627. [10. Delley, B., DMOL is a density functional theory (DFT) program distributed by Accelrys, Inc. J. Chem. Phys, 1990. 92: 508.

[11] Te Velde, G.t., et al., Chemistry with ADF. Journal of Computational Chemistry, 2001. 22(9): 931-967.

[12] Guerra, C.F., et al., Towards an order-N DFT method. Theoretical Chemistry Accounts, 1998. 99(6): 391-403.

[13]Te Velde, G. and E. Baerends, Precise density-functional method for periodic structures. Physical Review B, 1991. 44(15): 7888.

[14. Wiesenekker, G. and E. Baerends, Quadratic integration over the three-dimensional Brillouin zone. Journal of Physics: Condensed Matter, 1991. 3(35): 6721.

[15]Franchini, M., P.H.T. Philipsen, and L. Visscher, The Becke fuzzy cells integration scheme in the Amsterdam Density Functional program suite. Journal of computational chemistry, 2013. 34(21): 1819-1827.

[16]Franchini, M., et al., Accurate Coulomb Potentials for Periodic and Molecular Systems through Density Fitting. Journal of Chemical Theory and Computation, 2014. 10(5): 1994-2004.

[17]Ziegler, T. and A. Rauk, Carbon monoxide, carbon monosulfide, molecular nitrogen, phosphorus trifluoride, and methyl isocyanide as. sigma. donors and. pi. acceptors. A theoretical study by the Hartree-Fock-Slater transition-state method. Inorganic Chemistry, 1979. 18(7): 1755-1759.

[18]Ziegler, T. and A. Rauk, A theoretical study of the ethylene-metal bond in complexes between copper $(1+)$, silver $(1+)$, gold $(1+)$, platinum (0) or platinum $(2+)$ and ethylene, based on the Hartree-Fock-Slater transition-state method. Inorganic Chemistry, 1979. 18(6): 1558-1565.

[19]Ziegler, T. and A. Rauk, On the calculation of bonding energies by the Hartree Fock Slater method. Theoretical Chemistry Accounts: Theory, Computation, and Modeling (Theoretica Chimica Acta), 1977. 46(1): 1-10. 